\title{
Structural and Electrical Characterization of GaN Thin Films on Si(100)
}

\author{
Gajanan Niranjan Chaudhari*, Vijay Ramkrishna Chinchamalatpure, Sharada Arvind Ghosh \\ Nanotechnology Research Laboratory, Shri Shivaji Science College, Amravati, India \\ E-mail: "gnc4@indiatimes.com \\ Received July 13, 2011; revised September 23, 2011; accepted October 5, 2011
}

\begin{abstract}
The Gallium Nitride $(\mathrm{GaN})$ layers grown on silicon substrates by electron beam evaporation technique. Xray diffraction revealed that polycrystalline $\mathrm{GaN}$ was obtained indicating the enhance crystallinity of the films with annealing temperature at $600^{\circ} \mathrm{C}$. Crystalline quality of the $\mathrm{GaN}$ films was determined by Scanning Electron Microscopy (SEM). The crystalline size increases with increasing annealing temperature. The fabricated MIS structures were characterized using Capacitance-Voltage $(\mathrm{C}-\mathrm{V})$ measurements, the capacitance remains nearly constant over a large range in higher negative as well as over a large range in higher positive gate voltages and Current-Voltage (I-V) measurements shows low forward and reverse current possibly due to high density defect formation in the thin layer of gallium nitride during its growth.The film is characterized by X-Ray photoelectron spectroscopy (XPS). The XPS spectra show that formation of pure GaN without presence of elemental gallium and $\mathrm{Ga}_{2} \mathrm{O}_{3}$ in this film.
\end{abstract}

Keywords: Electron Beam Evaporation Technique, GaN Thin Film, C-V, I-V

\section{Introduction}

GaN (Gallium Nitride) have attracted interest due to their wide and direct band gap and their potential application to blue-ultraviolet light emitting devices, short-wavelength optoelectronic devices and high-power electrical devices [1]. Silicon is increasingly being used as a substrate for GaN growth [2,3] GaN deposited on silicon (Si) substrates has great advantages including excellent wafer quality, less hardness and more design flexibility with current silicon electronic circuit system [4-6]. The $\mathrm{Si}$ substrate for $\mathrm{GaN}$ growth has some advantages over other substrates. It can be obtained at low cost and the well developed Si growth technology ensures high quality $\mathrm{p}$ - and $\mathrm{n}$-type $\mathrm{Si}$ wafers. Furthermore, the hetero-epitaxial system of $\mathrm{GaN}$ on $\mathrm{Si}$ substrate can potentially combine the optoelectronic properties of $\mathrm{GaN}$ with those of highly advanced Si electronic devices. Direct growth of a GaN film on $\mathrm{Si}$ substrate results in either polycrystalline growth or a substantial diffusion of $\mathrm{Si}$ into the $\mathrm{GaN}$ film. Direct growth of a $\mathrm{GaN}$ film on $\mathrm{Si}$ substrate results in either polycrystalline growth or a substantial diffusion of Si into the GaN film. Thin AlN films have been used as buffer layers for GaN growth on Si substrate $[7,8]$. Threading dislocations and inversion domain boundaries usually form at the early stage of growth and then propagate through the film surface [9]. The initial growth mode and microstructure strongly depend on types of buffer layers [10-13], growth conditions, and growth methods [14-19]. Until now, little effort has been made to study the initial growth of $\mathrm{GaN}$ under different growth conditions.

\section{Experimental Details:}

The GaN thin films were grown on $\mathrm{Si}(100)$ substrates by using electron beam evaporation method. $\mathrm{Si}(100)$ was chosen due to its trigonal symmetry favoring epitaxial growth of the $\mathrm{GaN}(0001)$ plane. The substrate was cleaned by $5 \% \mathrm{HF}$ solution prior to the epitaxial growth. After a chemical cleaning process, the $\mathrm{Si}(100)$ substrate was heated to $1000^{\circ} \mathrm{C}$ under hydrogen ambient for 10 min to produce a clean, oxide-free surface to prevent the melt back etching of Si substrate.

The filament is used to activate the nitrogen gas and e-beam for evaporating gallium, water circulation is used for cooling purposes in a reaction chamber. The substrates are kept at a distance of $10 \mathrm{~cm}$ above the gallium source which is evaporated by electron beam. There is a tungsten filament heated at $2000^{\circ} \mathrm{C}$ by a dc supply in 
between gallium source and the substrates to activate the nitrogen gas the nitrogen gas is directed on to the hot filament. The $\mathrm{GaN}$ experimental samples were grown at room temperature, $300^{\circ} \mathrm{C}$ and $600^{\circ} \mathrm{C}$. The thickness of thin film GaN was $250 \mathrm{~nm}$, The contact of as-grown sample was deposited by e-gun evaporator. The annealing process was carried out at $800^{\circ} \mathrm{C}$ for 2 minutes to activate the sample and to provide the contact ohmic. The constant pressure $7 \times 10^{-5}$ Torr was maintained through out the deposition. The gallium was evaporated using an e-beam of energy and current $100 \mathrm{~mA}$. About $200 \mathrm{~nm}$ thick film of GaN were deposited on $\mathrm{Si}$ at the rate of $0.2 \mathrm{~nm} / \mathrm{s}$. Thickness was controlled by using a water cooling arrangement.

\section{Result and Discussion}

Figure 1 shows the X-ray diffraction (XRD) spectra of the GaN layer grown on $\mathrm{Si}$ substrates. The pattern for film grown at $300^{\circ} \mathrm{C}$ only reveal substrate peaks at $33.2^{\circ}$ and $69.3^{\circ}$ which correspond to $\mathrm{Si}(200)$ and $\mathrm{Si}(400)$ planes respectively. No X-ray diffraction peak corresponding to the crystalline phase of GaN was detected, suggesting an amorphous structure.

For the GaN film grown at $600^{\circ} \mathrm{C}$, weak peak was observed at $34.4^{\circ}$ which corresponds to (002) hexagonal wurtzite crystalline GaN. X-ray diffraction peaks observed for $\mathrm{GaN}$ is in good agreement with JCPDS data of the hexagonal crystalline GaN. The presence of strong and sharp GaN crystalline peaks were observed with increasing annealing temperature, the measured diffracttion peaks do not change significantly, but the intensity of these peaks becomes greater and sharper. This is due to the crystallite sizes becoming larger with evaluating

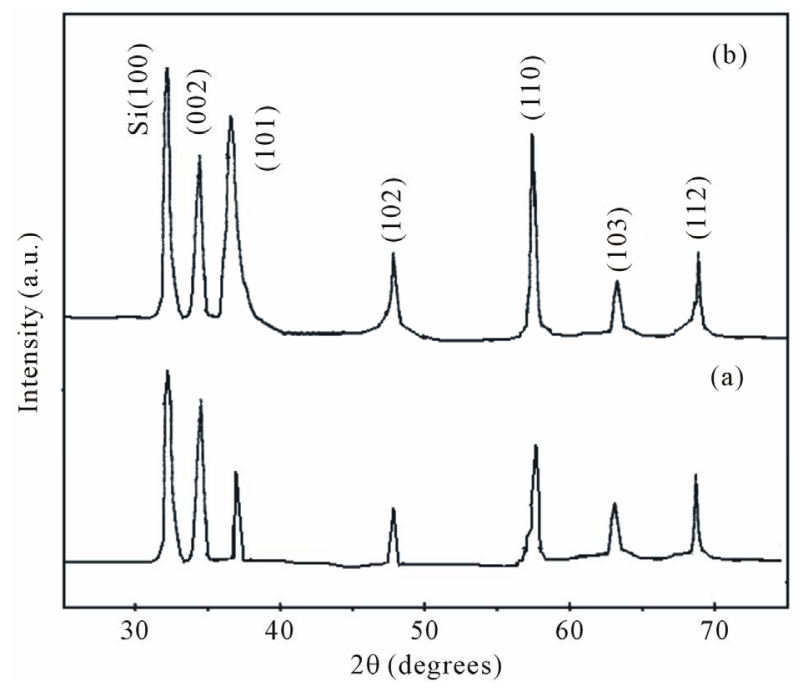

Figure 1. XRD Spectra of GaN thin film on Si (100) substrates annealed at (a) $300^{\circ} \mathrm{C}$ and at (b) $600^{\circ} \mathrm{C}$. the annealing temperature, these films are a mixed phase of crystalline and amorphous structure. This is probably a signature of the microcrystalline phase for GaN. The crystalline (grain) size determined is about $167 \mathrm{~nm}$, thus confirming the microcrystalline structure of the films.

Figure 2(a) shows the surface morphology of the samples by using SEM, there are small grains in the film annealing at $300^{\circ} \mathrm{C}$. This indicates that the mobility of $\mathrm{Ga}$ atoms is not large enough to make the grains grow large, so the crystallite size is limited by the diffusion length of Ga atoms. Figure 2(b) shows the pattern of the film that was grown at $600^{\circ} \mathrm{C}$. It can be seen that the crystalline size is larger than that of films shown in Figure 2(a) This is because the mobility of $\mathrm{Ga}$ atoms becomes larger with the increasing annealing temperature, thus it is possible to form larger grains. In the same way, the grains shown in Figure 2(b) are much larger than those in Figure 2(a) due to the higher annealing temperature. The grain size of the films is found to be about $200 \mathrm{~nm}$ in Figure 2(b).

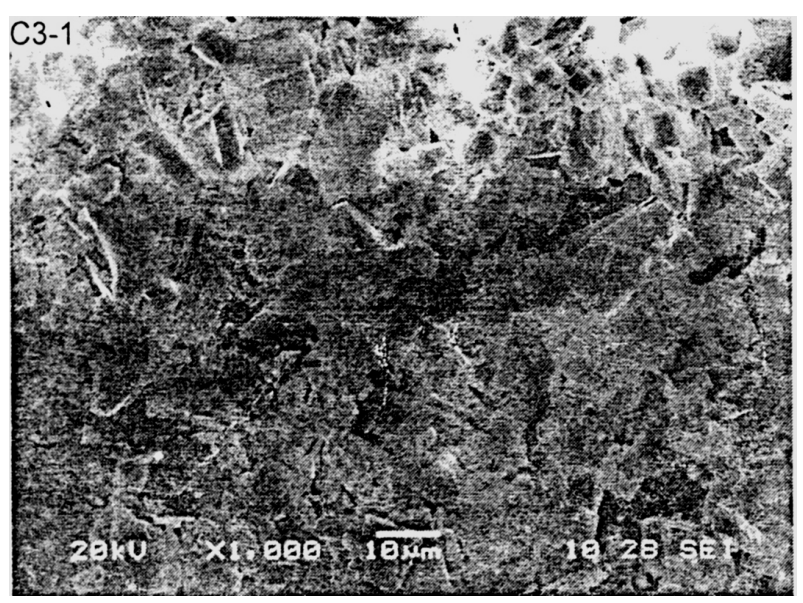

(a)

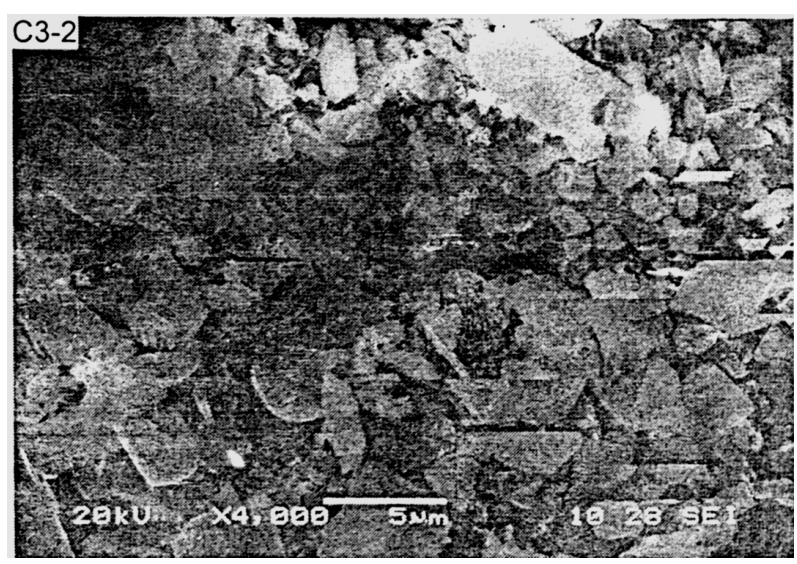

(b)

Figure 2. SEM micrograph of GaN thin film annealed at (a) $300^{\circ} \mathrm{C}$ and at (b) $600^{\circ} \mathrm{C}$. 
Figure 3 shows FTIR pattern for the sample (nitridated at $600^{\circ} \mathrm{C}, 8 \mathrm{~h}$ ) a clear absorption peak at $600 \mathrm{~cm}^{-1}$ due to $\mathrm{GaN}$ bond stretch was presented. It has been reported that $\mathrm{GaN}$ absorbs infrared light at near $1100 \mathrm{~cm}^{-1}$ with shoulder at $1200 \mathrm{~cm}^{-1}$ due to Si-O bond stretching vibration and at 816 and $446 \mathrm{~cm}^{-1}$ due to ring structure. All the above I R absorptions of pure $\mathrm{Si}$ are identified in the spectrum of composite at 1220, 900, 600 and 460 $\mathrm{cm}^{-1}$ respectively. No other strong peaks were presented in the pattern. It indicated that the element Ga dominantly existed with Ga-N bond in the samples.

\section{Electrical Characterization}

Figure 4 shows the capacitance-voltage $(\mathrm{C}-\mathrm{V})$ measurements of the fabricated MIS structures at room temperature, $300^{\circ} \mathrm{C}$ and $600^{\circ} \mathrm{C}$ on the $\mathrm{GaN}$ thin film deposited at $650^{\circ} \mathrm{C}$. It is observed that, the capacitance remains nearly constant over a large range in higher negative as well as over a large range in higher positive gate voltages indicating a formally pinned surface. However, the capacitance was found to be higher in the negative but lower in the positive gate voltage. Further the capacitance was found to be higher for the thin film GaN at $300^{\circ} \mathrm{C}$ in both the zones. The sudden decrease in capacitance at $0 \mathrm{~V}$ is due to defect density in the film and also due to the semiconductor fermi level is not properly pinned at the interface. These measurements demonstate that the $\mathrm{Al} / \mathrm{GaN} / \mathrm{Si}(111)$ system possesses the charge control needed for insulated gate field effect transistor operation with a higher dielectric constant.

In this study, Current -Voltage (I-V) measurements were made on MIS structure fabricated by evaporating $2000 \mathrm{~A}^{\circ}$ of $\mathrm{Al}$ on $\mathrm{GaN}$ layers deposited on $\mathrm{Si}(100)$ substrate. Figure 5 shows the results of a typical measurement performed at $300^{\circ} \mathrm{C}$. The Current-Voltage characteristics shows low forward and reverse current possibly

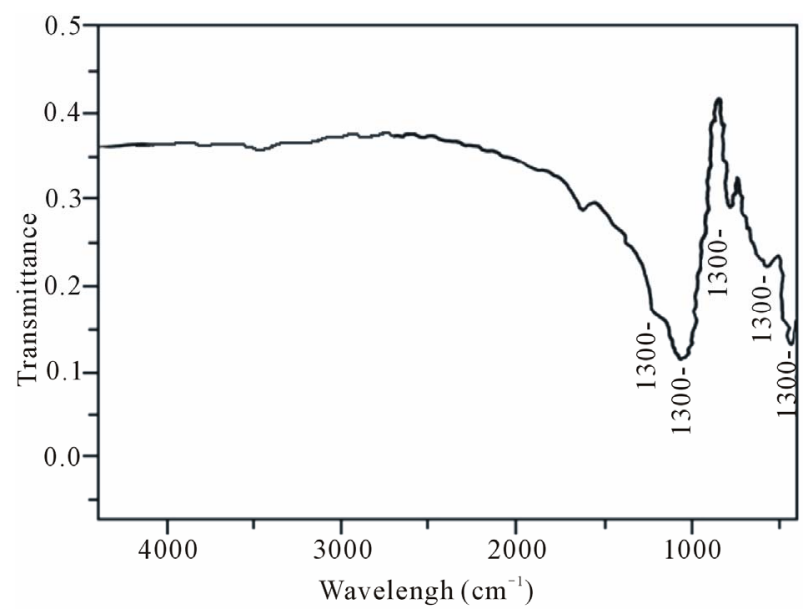

Figure 3. FTIR Spectra of GaN thin film as deposited.

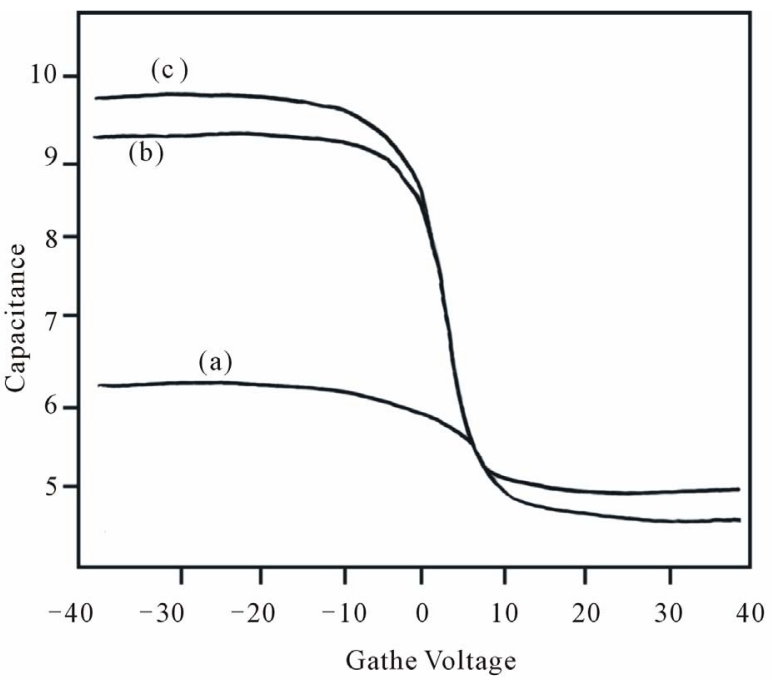

Figure 4. C-V characteristics of GaN thin film on Si at different temperature (a) as deposited (b) at $300^{\circ} \mathrm{C}$ (c) at $600^{\circ} \mathrm{C}$.

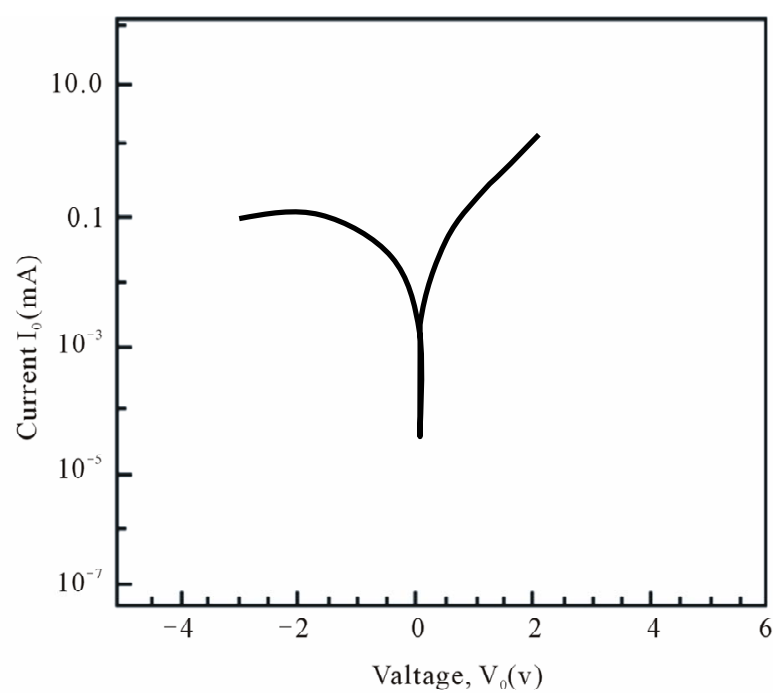

Figure 5. The I-V characteristics of GaN thin film at $300^{\circ} \mathrm{C}$.

due to high density defect formation in the thin layer of gallium nitride during its growth. The leakage current is high at $300^{\circ} \mathrm{C}$, had not damaged the sample. The actual nature of the metal-semiconductor contact is not controllable and in fact may vary substantially from one process to another.

Figure 6 shows the room temperature photoluminescence spectra of $\mathrm{GaN}$ film which was annealed at $300^{\circ} \mathrm{C}$. The PL spectrum shows an emission at $353 \mathrm{~nm}(3.5 \mathrm{eV})$ for room temperature measurement. The resulting film exhibits a blue-shift in the optical band gap relative to $\mathrm{GaN}(3.4 \mathrm{eV})$. It may be explained by quantum confinement model [20]. Both the optical excitation and recombination take place in the nanometer grain, and the energy gap of the grain is enlarged due to the quantum con- 


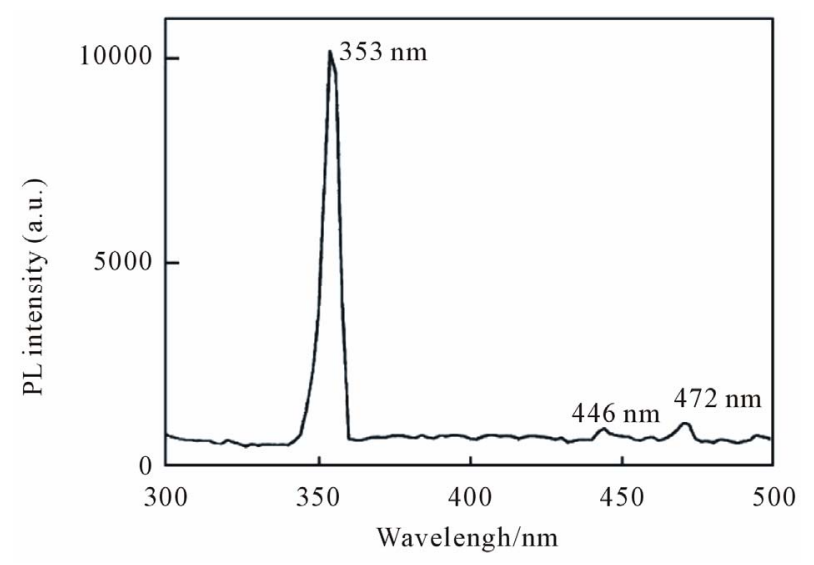

Figure 6. The photoluminesce spectra of GaN.

finement effect. In addition, two other emissions can be observed, which peaked at $446 \mathrm{~nm}$ and $472 \mathrm{~nm}$ respecttively. The $446 \mathrm{~nm}$ peak results from radiative recombinations related to the tail region, and the other peak comes from localized states which are attributed to deep traps like nitrogen vacancies [21].

Figure 7 shows the X-ray photoelectron spectra of N $1 \mathrm{~s}, \mathrm{Ga} 2 \mathrm{p}$ and $\mathrm{Ga} 3 \mathrm{~d}$ for films grown at the annealing temperature of $600^{\circ} \mathrm{C}$. As can be observed, the $\mathrm{N} 1 \mathrm{~s}$ signal shown in Figure 7(a) contains a main peak centered at $397.5 \mathrm{eV}$. The width and slight asymmetry of the $\mathrm{N} 1 \mathrm{~s}$ peak is attributed to the possible presence of nitrogen in $\mathrm{GaN}$ [22]. Ga 2 $\mathrm{p}_{3 / 2}$ and $\mathrm{Ga} 2 \mathrm{p}_{1 / 2}$ peaks are shown in Figure 7(b) with binding energies of 1117 and $1143.2 \mathrm{eV}$ respectively. The core level values of gallium were found to have a positive shift with respect to elemental gallium. Dinescu et al. [23] and Elkashef et al. [22] have reported the values of the $\mathrm{Ga} 2 \mathrm{p}_{3 / 2}$ peak at $1117 \mathrm{eV}$ and $1119.2 \mathrm{eV}$ in their GaN films respectively. Figure 7(c) shows Ga 3d spectra for the films. No bond formation between $\mathrm{Ga}$ and $\mathrm{O}$ was observed since the $\mathrm{Ga} 3 \mathrm{~d}$ spectrum did not show any peak corresponding to $\mathrm{Ga}_{2} \mathrm{O}_{3}$ as reported by Ishikaua et al. [24]. The above results confirm the formation of pure $\mathrm{GaN}$ without the presence of elemental gallium and $\mathrm{Ga}_{2} \mathrm{O}_{3}$ in this film.

\section{Conclusions}

GaN thin film has been deposited on Si (100) by using electron beam evaporation method. The GaN/Si (100) structures were studied by structural and electrical characteristics. The XRD and SEM of GaN/Si(100) indicates the enhance crystallinity of the films with annealing temperature at $600^{\circ} \mathrm{C}$. The $\mathrm{C}-\mathrm{V}$ measurement of $\mathrm{GaN}$ thin film deposited on $\mathrm{Si}(100)$ annealed at $600^{\circ} \mathrm{C}$ shows large frequency dispersion in the accumulation region. The Current-Voltage (I-V) measurement shows low forward and reverse current possibly due to high density defect

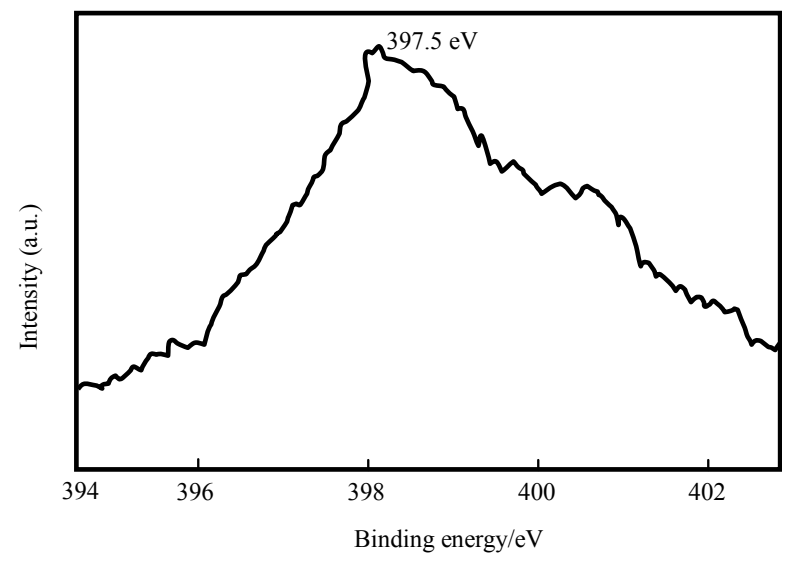

(a)

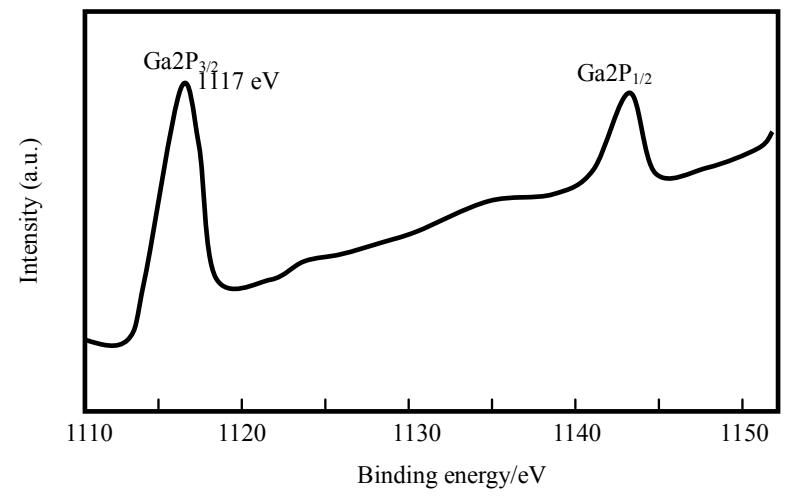

(b)

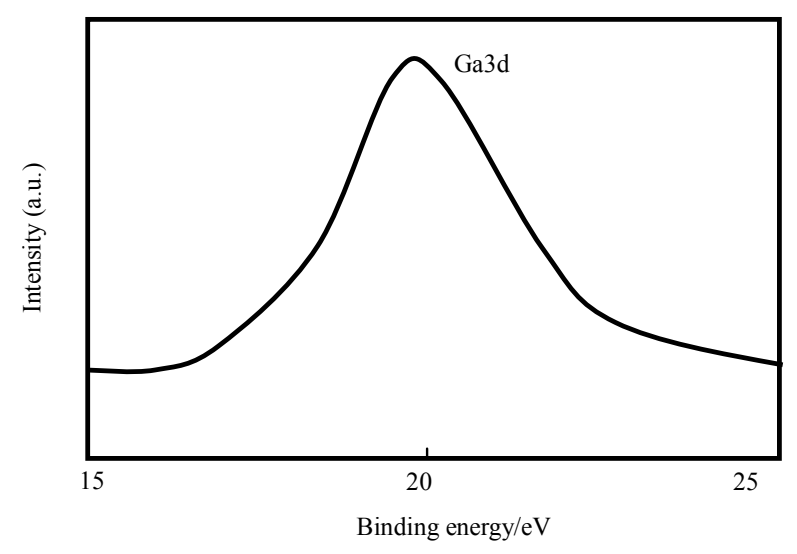

(c)

Figure 7. It shows the XPS spectra of GaN thin film on Si (a) N 1s; (b) Ga 2p; (c) Ga 3d peaks for the film.

formation in the thin layer of gallium nitride during its growth. The XPS spectra show that formation of pure GaN without presence of elemental gallium and $\mathrm{Ga}_{2} \mathrm{O}_{3}$ in this film.

\section{References}

[1] S. C. Jain, M. Willander, J. Narayan and R. Van Over- 
straeten, "III-Nitride: Growth, Characterisation and Properties," Journal of Applied Physics, Vol. 87, No. 3, 2000, pp. 965-1006. doi:10.1063/1.371971

[2] J. W. Yang, A. Lunev, G. Simin, A. Chitnis, M. Shatalov, M. A. Khan, J. E. Van Nostrand and R. Gaska, "Selective Area Deposited Blue GaN-InGaN Multiple-Quantum Well Light Emitting Diodes over Silicon Substrates," Applied Physics Letters, Vol. 76, No. 3, 2000, pp. 273-275. doi:10.1063/1.125745

[3] A. Dadgar, J. Christen, T. Riemann, S. Richter, J. Blaesing, A. Diez, A. Krost, A. Alam and M. Heuken, "Formation of Thin GaN Layer on Si(111) for Fabrication of High Temperature Metal Field Effect Transistors," Applied Physics Letters, Vol. 78, No. 15, 2001, p. 2211. doi:10.1063/1.1362327

[4] J. W. Yang, C. J. Sun, Q. Chen, M. Z. Anwar, M. A. Khan, S. A. Nikishin, G. A. Seryogin, A. V. Qsinsky, L. Chernyak, H. Temkin, C. Hu and S. Mahajan, "High Quality GaN-InGaN Heterostructures Grown on $\mathrm{Si}(111)$ Substrates," Applied Physics Letters, Vol. 69, No. 23, 1996, pp. 3566-3568. doi:10.1063/1.117247

[5] N. P. Kobayashi, J. T. Kobayashi, P. D. Dapkus, W. J. Choi, A. E. Bond, X. Zhang and D. H. Rich, "GaN Growth on Si(111) Substrate Using Oxidized AlAs as an Intermediate Layer," Applied Physics Letters, Vol. 71, No. 24, 1997, pp. 3569-3571. doi:10.1063/1.120394

[6] L. Wang, X. Liu, Y. Zan, J. Wang, D. Wang, D. Lu and Z. Wang, "Wurtzite GaN Epitaxial Growth on a $\mathrm{Si}(001)$ SubStrate Using $\gamma-\mathrm{Al}_{2} \mathrm{O}_{3}$ as an Intermediate Layer," $A p$ plied Physics Letters, Vol. 72, No. 1, 1998, pp. 109-111. doi: $10.1063 / 1.120660$

[7] P. W. Deelmann, R. N. Bicknell-Tassius, S. Nikishin, V. Kuryatkov and H. Temkin, "Low-Noise GaN Schottky Diodes on $\mathrm{Si}(111)$ by Molecular Beam Epitaxy," Applied Physics Letters, Vol. 78, No. 15, 2001, p. 2172. doi:10.1063/1.1357448

[8] Y. Hiroyama and M. Tamura, "Effect of Very Thin SiC Layer on Heteroepitaxial Growth of Cubic GaN on $\mathrm{Si}$ (001)," Japanese Journal of Applied Physics, Vol. 37, 1998, pp. 630-632. doi:10.1143/JJAP.37.L630

[9] L. T. Romano, J. E. Northrup and M. A. O'Keefe, "Inversion Domains in GaN Grown on Sapphire," Applied Physics Letters, Vol. 69, No. 16, 1996, pp. 2394-2396. doi: $10.1063 / 1.117648$

[10] C. Stampfl, J. Neugebauer and C. Van de Walle, "Doping of AlxGa1-xN Alloys," Material Science Engineering, Vol. 59, 1999, pp. 253-257.

[11] C. Wang and R. F. Davis, "Deposition of Highly Resistive, Undoped, and P-Type, Magnesium-Doped Gallium Nitride Films by Modified Gas Source Molecular Beam Epitaxy," Applied Physics Letters, Vol. 63, No. 7, 1993, pp. 990-992. doi:10.1063/1.109816

[12] K. Okamoto, H. Ohta, S. F. Chichibu, J. Ichihara and H. Takasu, "Continuous-Wave Operation of $m$-Plane InGaN Multiple Quantum Well Laser Diodes,” Japanese Journal of Applied Physics, Vol. 46, 2007, pp. L187-L189. doi:10.1143/JJAP.46.L187

[13] J. I. Pankove and T. D. Moustakas, "Gallium Nitride GaN, Semiconductors and Semimetals," Academic Press, Waltham, 1998.

[14] G. Martin, A. Botchkarev, A. Rockett and H. Morkoc, "Valence-Band Discontinuities of wurtzite GaN, AlN, and InN Heterojunctions Measured by X-Ray Photoemission Spectroscopy," Applied Physics Letters, Vol. 68, No. 18, 1996, pp 2541-2543. doi:10.1063/1.116177

[15] E. T. Yu and M. O. Manasreh, "III-V Nitride Semi-conductors Applications and Devices," Taylor \& Francis, New York, 2003.

[16] M. O. Manasreh and I. T. Ferguson, "III-V Nitride Semiconductors Growth," Taylor \& Francis, New York, 2003.

[17] M. H. Kim, Y. G. Do, H. C. Kang, D. Y. Noh and S.-J. Park, "Effects of Step-Graded $\mathrm{Al}_{x} \mathrm{Ga}_{1-x} \mathrm{~N}$ Interlayer on Properties of GaN Grown on $\mathrm{Si}(111)$ Using Ultrahigh Vacuum Chemical Vapor Deposition," Applied Physics Letters, Vol. 79, No. 17, 2001, pp. 2713-2715. doi:10.1063/1.1412824

[18] J. Wan, R. Venugopal, M. R. Melloch, H. W. Liaw and W. J. Rummel, "Growth of Crack-Free Hexagonal GaN Films on Si(100)," Applied Physics Letters, Vol. 79, No. 10, 2001, pp. 1459-1461. doi:10.1063/1.1400770

[19] A. J. Steckl, J. Devrajan, C. Tran and R. A. Stall, "SiC Rapid Thermal Carbonization of the Si(111) Semiconductor-on-Insulator Structure and Subsequent Metalorganic Chemical Vapor Deposition of GaN," Applied Physics Letters, Vol. 69, No. 15, 1996, pp. 2264-2266. doi:10.1063/1.117528

[20] L. T. Canham, "Silicon Quantum Wire Array Fabrication by Electrochemical and Chemical Dissolution of Wafers," Applied Physics Letter, Vol. 57, No. 10, 1990, pp. 1046-1048. doi:10.1063/1.103561

[21] K. Abe, S. Nonomura and S. Kobayashi, "Photoluminescence Study of Nano-Crystalline GaN and AlN Grown by Reactive Sputtering," Journal of Non-Crystalline Solids, Vol. 227-230, 1998, pp. 1096-1100. doi:10.1016/S0022-3093(98)00293-2

[22] N. Elkashef, R. Srinivasa and S. Major, "Sputter Deposition of Gallium Nitride Films Using a GaAs Target," Thin Solid Films, Vol. 333, No. 1-2, 1998, pp. 9-12. doi:10.1016/S0040-6090(98)00550-1

[23] M. Dinescu, P. Verardi and C. Boulmer-Leborgne, "GaN Thin Films Deposition by Laser Ablation of Liquid Ga Target in Nitrogen Reactive Atmosphere," Applied Surface Science, Vol. 127-129, 1998, pp. 559-563. doi:10.1016/S0169-4332(97)00705-8

[24] H. Ishikaua, S. Kobayashi and Y. Koide, "Effects of Surface Treatments and Metal Work Functions on Electrical Proper- ties at p-GaN/Metal Interfaces, Effects of Surface," Journal of Applied Physics, Vol. 81, No. 3, 1997, pp. $1315-1322$. $\underline{\text { doi: } 10.1063 / 1.363912}$ 